\title{
ASPECTOS BIOLÓGICOS DE Chrysoperla externa (Hagen, 1861) (Neuroptera: Chrysopidae) EM CASA-DE-VEGETAÇÃO
}

\author{
KATIA GISELE BRASIL BOREGAS ${ }^{1}$ \\ CÉSAR FREIRE CARVALHO \\ BRÍGIDA SOUZA ${ }^{2}$
}

\begin{abstract}
RESUMO - Objetivou-se estudar em casa-devegetação alguns aspectos biológicos das fases imaturas e adulta de Chrysoperla externa (Hagen), alimentando suas larvas com ovos do piralídeo Anagasta kuehniella (Zeller) e os adultos com dietas artificiais. O período embrionário foi determinado utilizando-se tubos de vidro de 2,5 x 8,5 cm, gaiola plástica transparente de $2,5 \times$ $1,0 \mathrm{~cm}$ e tubo de pvc de $10,0 \times 10,0 \mathrm{~cm}$ (com e sem umidificador). Os aspectos biológicos das fases de larva e pupa foram determinados confinando-as em tubos de vidro e gaiolas plásticas e os adultos em gaiolas de pvc de 10,0 x 10,0 cm, alimentando-os com lêvedo de cerveja + mel, extrato de soja + mel e pólen + mel, nas consistências semilíquida e pastosa. $\mathrm{O}$ período embrionário não foi influenciado pelo tipo de recipiente, variando de 6,3 $\pm 0,2$ a 7,6 $\pm 0,7$ dias. Quando os ovos foram mantidos nas gaiolas plásticas, a viabilidade foi de $71,0 \%$; contudo, naquelas de pvc e sem umidificador, obtiveram-se $88,0 \pm 5,0 \%$. A duração do primeiro e segundo ínstares não foi influenciada pelo tipo de recipiente; larvas de terceiro ínstar confinadas em tubos de
\end{abstract}

vidro apresentaram uma duração de $2,3 \pm 0,1$ dias e aquelas criadas em gaiolas plásticas de 1,6 $\pm 0,1$ dias. A maior capacidade predatória $(2.630,0 \pm 224,8$ ovos $)$ foi obtida para larvas de terceiro ínstar mantidas em tubos de vidro, constatando-se um consumo de 1.919,9 \pm 151,6 ovos quando mantidas em gaiolas plásticas fixadas em folhas do algodoeiro. A duração e a viabilidade dessa fase também não foram influenciadas pelo tipo de recipiente de criação, com uma variação de 5,5 $\pm 0,4$ a $6,1 \pm 0,4$ dias e $67,9 \pm 3,9$ a $74,4 \pm 3,9 \%$, respectivamente. A duração e a viabilidade da fase de pupa não foram afetadas pelo tipo de gaiola, constatando-se uma média de 13,5 \pm 0,3 dias e $60 \%$ de pupas viáveis. Com relação à fase adulta, verificou-se que a dieta constituída por lêvedo de cerveja + mel, na forma semilíquida ou pastosa, proporcionou os melhores resultados, obtendose uma fecundidade total de 387,8 $\pm 86,2$ e 221,0 $\pm 41,4$ ovos/fêmea, respectivamente. As fêmeas alimentadas com esse mesmo tipo de dieta na forma semilíquida foram as mais longevas, vivendo cerca de 45 dias.

TERMOS PARA INDEXAÇÃO: Aspectos biológicos, Chrysoperla externa, dieta artificial, casa de vegetação.

\section{BIOLOGICAL ASPECTS OF Chrysoperla externa (Hagen, 1861) (Neuroptera: Chrysopidae) IN GREENHOUSE}

\begin{abstract}
This work was developed with the goal to study in greenhouse, some biological aspects of the immature and adult stages of Chrysoperla externa (Hagen), feeding its larvae with eggs of Anagasta kuehniella (Zeller) and adults with artificial diets. The embryonic period was determined by utilizing glass tubes of $2.5 \times 8.5 \mathrm{~cm}$, transparent plastic cage of $2.5 \mathrm{x}$ $1.0 \mathrm{~cm}$ and pvc tube of $10.0 \times 10.0 \mathrm{~cm}$ (with and without humidifier). The biological aspects of the larval and pupal stage were determined by confining them in glass tubes and plastic cages and the adults in pvc cages
\end{abstract}

of 10.0 × $10.0 \mathrm{~cm}$, feeding them with diets: yeast + honey, soy extract + honey and pollen + honey, at two consistencies, semi-liquid and pasty. The embryonic period was not influenced by the sort of container, ranging from $6.3 \pm 0.2$ to $7.6 \pm 0.7$ days. When the eggs were kept in the plastic cages, the percentage of hatching was $71 \%$, however, in those of pvc and without a humidifier the mean was of $88.0 \pm 5.0 \%$. The duration of the $1^{\text {st }}$ and $2^{\text {nd }}$ instars was not influenced by the type of rearing container, $3^{\text {rd }}$ instar larvae confined in glass tubes presented a duration of $2.3 \pm 0.1$ days

\footnotetext{
1. Engenheiro Agrônomo, MS, UNIVERSIDADE FEDERAL DE LAVRAS/UFLA, Departamento de Entomologia, Caixa Postal 37 - 37200-000 - Lavras, MG.

2. Professores do Departamento de Entomologia/UFLA.
} 
and those reared in plastic cages the mean was of $1.6 \pm$ 0.1 days. The greatest predatory capacity (2630.0 \pm 224.8 eggs) was obtained for larvae of $3^{\text {rd }}$ instar kept in glass tubes and of $1919.9 \pm 151.6$ eggs when kept in plastic cages fixed on cotton plant leaves. Both the duration and survival rate of that stage were not influenced by the sort of rearing container with a range of $5.5 \pm 0.4$ to $6.1 \pm 0.4$ days and $67.9 \pm 3.9$ to $74.4 \pm$
$3.9 \%$, respectively. The duration and survival of the pupa stage were not affeted by the type of cage being of $13.5 \pm 0.3$ days and $60 \%$ of adults emerged. The diet made up of yeast + honey in either the liquid or the pasty form showed the best results with a total fecundity of $387.8 \pm$ 86.2 and $211.0 \pm 41.4$ eggs/female, respectively. The females fed on that same type of diet in the liquid form had higher longevity, living about 45 days.

INDEX TERMS: Biological aspects, green lacewings, artificial diets, greenhouse.

\section{INTRODUÇÃO}

É de fundamental importância o conhecimento dos insetos que causam danos econômicos às plantas cultivadas e de seus predadores, parasitóides e patógenos, os quais auxiliam no controle natural. Entre os primeiros, têm sido mencionadas algumas espécies de Neuroptera: Chrysopidae como organismos responsáveis pela regulação da densidade populacional de insetos-praga tanto em casa-de-vegetação como em diversas culturas no campo. Para que se tenha sucesso quanto à utilização desses predadores como agentes de controle biológico, são necessários conhecimentos básicos sobre a sua biologia, não somente para criação e manutenção em laboratório, como também para garantir o seu desenvolvimento em condições de campo.

Uma das espécies mais comuns e mais estudadas na Região Neotropical é Chrysoperla externa (Hagen, 1861). A facilidade com que esses insetos podem ser criados em laboratório permite o incremento das técnicas para a sua produção visando a atender as demandas, não apenas para as criações de manutenção, pesquisa e comercial, como também, para criação massal. Um dos aspectos que devem ser considerados refere-se ao tipo de dieta e de recipiente utilizados para a criação de larvas e adultos (Carvalho \& Souza, 2000).

Considerando que a maioria das pesquisas até então realizadas com $C$. externa foi desenvolvida em condições de laboratório, objetivou-se estudar em casa de vegetação:

1. o efeito da umidade relativa do ar no interior de recipientes de criação sobre a fase de ovo;

2. o efeito da temperatura e da umidade relativa do ar sobre a fase de larva;

3. a influência de diferentes tipos de recipientes de criação sobre alguns aspectos biológicos das fases imaturas; 4. o efeito de dietas artificiais fornecidas nas consistências semilíquida e pastosa sobre a capacidade reprodutiva desse crisopídeo.

\section{MATERIAL E MÉTODOS}

A pesquisa foi realizada em casa-de-vegetação a partir de adultos de $C$. externa oriundos de uma criação de laboratório, utilizando-se, para as fases de larva e pupa, dois tipos de recipientes. O primeiro foi constituído de tubos de vidro de $2,5 \mathrm{~cm}$ de diâmetro $\mathrm{x} 8,5 \mathrm{~cm}$ de altura, vedados com pvc laminado. O segundo constou de uma gaiola confeccionada em matéria plástica transparente com 2,5 cm de diâmetro x $1,0 \mathrm{~cm}$ de altura, com sua extremidade superior fechada com organza branca e a inferior apoiada sobre uma folha de algodoeiro da cultivar IAC-20 mantida em um vaso plástico de 51 (Figura 1). A fixação da gaiola na folha foi feita por uma presilha de metal e na superfície abaxial foi colocada uma base plástica rígida de $3,0 \times 3,0 \mathrm{~cm}$, a qual impediu eventuais dobras da superfície foliar e a fuga da larva. Com o objetivo de se evitar uma possível ruptura do pecíolo, as folhas contendo as gaiolas foram apoiadas em um suporte de madeira fixado no substrato do vaso. Nessas fases, foram avaliadas a duração, viabilidade e capacidade predatória de ovos de Anagasta kuehniella (Zeller, 1879) (Lepidoptera: Pyralidae) em cada ínstar do predador. Os ovos do piralídeo foram fornecidos em uma fita adesiva de $1 \mathrm{~cm}^{2}$, com o objetivo de facilitar a sua contagem.

$\mathrm{O}$ efeito da temperatura e da umidade relativa do ar sobre a fase de larva foi avaliado mediante análises de correlações de Pearson. Os registros desses fatores foram feitos por um termohigrógrafo colocado próximo ao experimento, em local protegido da incidência direta dos raios solares, e as determinações médias diárias, feitas de acordo com a metodologia proposta em Climanálise (1998).

Para a fase de ovo, utilizou-se, além dos recipientes mencionados anteriormente, um terceiro tipo constituído por um tubo de pvc com $10 \mathrm{~cm}$ de diâmetro x $10 \mathrm{~cm}$ de altura, cuja extremidade superior foi fechada com organza branca e a inferior com pve laminado, sendo o conjunto apoiado em uma placa de Petri de 15 $\mathrm{cm}$. Com o objetivo de testar a influência da umidade

Ciênc. agrotec., Lavras. V.27, n.1, p.7-16, jan./fev., 2003 
relativa do ar sobre o período embrionário e viabilidade, utilizou-se, nesse tipo de recipiente, um umidificador formado por um frasco de vidro de $10 \mathrm{ml}$ contendo um chumaço de algodão embebido em água destilada.

$\mathrm{Na}$ fase adulta, utilizaram-se insetos recémemergidos oriundos da criação de laboratório, os quais foram separados em casais e transferidos para gaiolas cilíndricas de pvc de $10 \mathrm{~cm}$ de diâmetro x $10 \mathrm{~cm}$ de altura, apoiadas em placas de Petri forradas com papel filtro branco. As unidades de criação foram revestidas internamente com o mesmo tipo de papel, que foi usado como substrato de oviposição e, para permitir a ventilação, foram fechadas com tecido de malha fina.

Nessa fase, foram avaliados os períodos de préoviposição, oviposição, efetivo de oviposição, número diário e total de ovos e longevidade, para adultos alimentados com as dietas: lêvedo de cerveja + mel (LCM), extrato de soja + mel (ESM) e pólen + mel (PM), nas consistências semilíquida e pastosa. No seu preparo, foram adicionados $30 \%$ de água destilada para a obtenção da consistência semilíquida e $0,5 \%$ para a consistência pastosa. Na dieta semilíquida, utilizou-se 1,0 g de ácido ascórbico para cada $100 \mathrm{ml}$ de dieta, visando a prevenir possíveis contaminações. O pólen utilizado nesse experimento foi obtido por meio de um coletor adaptado a uma caixa de criação do Apiário Central da UFLA, oriundo, portanto, de diversas espécies vegetais.

As dietas foram fornecidas em um recipiente plástico de 0,2 ml e renovadas a cada 48 horas. Em um frasco de $10 \mathrm{ml}$, foi usada uma espuma de poliuretano embebida em água destilada, reposta duas vezes ao dia em função das condições climáticas na casa-devegetação.

Os recipientes de criação foram colocados sobre uma bancada de metal e, para evitar a incidência direta dos raios solares, utilizou-se um sombrite a $50 \%$ fixado a $100 \mathrm{~cm}$ de altura das unidades experimentais. Contra um eventual ataque por formigas, empregou-se um suporte de madeira de $100 \mathrm{~cm}$ de comprimento por $80 \mathrm{~cm}$ de largura, apoiado sobre quatro tubos de pvc de $10 \mathrm{~cm}$ de altura, os quais foram mantidos no interior de uma bandeja metálica contendo água e algumas gotas de detergente.

Para as fases imaturas, o delineamento experimental foi o inteiramente casualizado, com os tratamentos representados pelos tipos de recipientes de criação, com dez repetições constituídas por dez indivíduos, e na fase adulta utilizou-se um esquema fatorial, sendo os tratamentos representados pelas dietas, nas duas consistências, com cinco repetições. Os dados obtidos para as viabilidades das fases de ovo, larva e pupa foram corri- gidos para arco seno $\sqrt{x}$ e aqueles referentes à fase adulta transformados para $\sqrt{x+0,5}$ antes de se proceder à análise de variância e ao teste de média de Scott e Knott a P $\leq$ 0,05 (Scott \& Knott, 1974).

\section{RESULTADOS E DISCUSSÃO}

Quando os ovos foram mantidos nas quatro condições estudadas, o período embrionário variou de $6,3 \pm$ 0,2 a 7,6 \pm 0,7 dias, evidenciando que o tipo de gaiola e a umidificação do ambiente não interferiram de maneira significativa na duração dessa fase (Tabela1).

Nos diversos tipos de recipientes, a viabilidade dos ovos não foi inferior a $70 \%$, verificando-se que aqueles mantidos na gaiola de pvc sem umidificador apresentaram a maior viabilidade $(88,0 \pm 5,0 \%)$, diferindo significativamente das demais (Tabela 1). Esses resultados aproximaram-se dos obtidos por Figueira et al. (2001), que constataram, para ovos de C. externa criada em laboratório, uma viabilidade próxima a $83 \%$ em temperaturas na faixa de 24 a $30^{\circ} \mathrm{C}$.

Constatou-se uma sensibilidade dos ovos de $C$. externa às condições de umidade relativa quando se utilizaram as gaiolas de pvc com e sem umidificador. Embora tenham sido vedadas com organza, que permite a troca de ar entre o ambiente interno e externo do recipiente, a viabilidade dos ovos foi afetada negativamente pela concentração de umidade no ar. Tais observações são coincidentes com aquelas efetuadas por Gitirana Neto et al. (2001) e Souza \& Carvalho (2001), que constataram, em experimentos realizados em condições de campo durante quatro anos consecutivos, uma redução significativa na densidade populacional de adultos de crisopídeos em épocas com precipitação pluviométrica e umidade relativa do ar mais elevadas. Possivelmente, esses fatores climáticos são limitantes, não somente para a sua ocorrência, como também para a sua sobrevivência em condições naturais.

A duração do primeiro e segundo ínstares não diferiu significativamente em função do tipo de recipiente utilizado. O terceiro ínstar, ao contrário dos demais, foi maior em tubos de vidro com $2,3 \pm 0,1$ dias, ao passo que na gaiola plástica foi de 1,6 $\pm 0,1$ dias. A duração do primeiro ínstar de larvas criadas em gaiola plástica foi superior à do segundo e terceiro ínstares, porém, aquelas que foram mantidas em tubos de vidro apresentaram o primeiro e terceiro ínstares significativamente mais longos que o segundo (Tabela 2).

Os resultados das análises de correlação mostraram que não houve efeito da temperatura e da umidade 
relativa do ar na duração de cada ínstar. As oscilações da temperatura ocorreram entre 15 e $27^{\circ} \mathrm{C}$, e da umidade relativa entre 65 e 90\%, durante o início do mês de novembro, quando se procederam às avaliações dessa etapa do experimento. Contudo, essas oscilações não foram suficientes para afetar a velocidade do desenvolvimento larval. Observou-se que o tipo de recipiente também não afetou a duração dos ínstares, porém, esse parâmetro foi afetado pelo estádio de desenvolvimento das larvas, constatando-se uma relação inversa entre eles, caracterizada por uma redução na sua duração em função do desenvolvimento larval (Tabela 3).

O estudo da influência dos ínstares na capacidade predatória evidenciou que o consumo no primeiro e segundo estádios não diferiu em função do tipo de recipiente. No terceiro, larvas criadas em tubo de vidro consumiram 2.630,0 $\pm 224,8$ ovos, diferindo do consumo verificado em gaiolas plásticas, que foi de 1.919,9 \pm 151,6 ovos, diferença essa que pode estar relacionada à menor duração do terceiro ínstar verificada para larvas criadas em gaiolas plásticas $(1,6 \pm 0,1$ dias $)$ em relação àquelas criadas em tubos de vidro $(2,3 \pm 0,1$ dias). Avaliando-se o número de ovos predados em cada ínstar nos dois tipos de recipientes, observou-se que as larvas criadas em tubos de vidro apresentaram maior consumo no terceiro, não havendo diferença entre o primeiro e o segundo ínstares. Da mesma forma, larvas de terceiro ínstar criadas em gaiolas plásticas apresentaram o maior consumo, seguidas pelas de segundo e de primeiro ínstar (Tabela 2). Esses resultados discreparam daqueles obtidos por Aun (1986), que verificou um consumo total de 36, 139 e 902 ovos de A. kuehniella em cada ínstar de C. externa criada em tubos de vidro semelhantes, respectivamente.

A análise de correlação entre a capacidade predatória e o tipo de recipiente mostrou que esse fator não influenciou o consumo, o mesmo ocorrendo com a umidade relativa, que não exerceu nenhuma influência sobre o número de ovos predados. Por outro lado, observou-se que a correlação entre os ínstares e o consumo foi significativa e positiva, caracterizando um aumento no número de ovos predados em função do desenvolvimento larval, o que já era esperado, uma vez que larvas em estádios mais avançados de desenvolvimento são capazes de capturar um maior número de presas em conseqüência dos menores tempos de busca e de manuseio, conforme constatado por Fonseca et al. (2000).

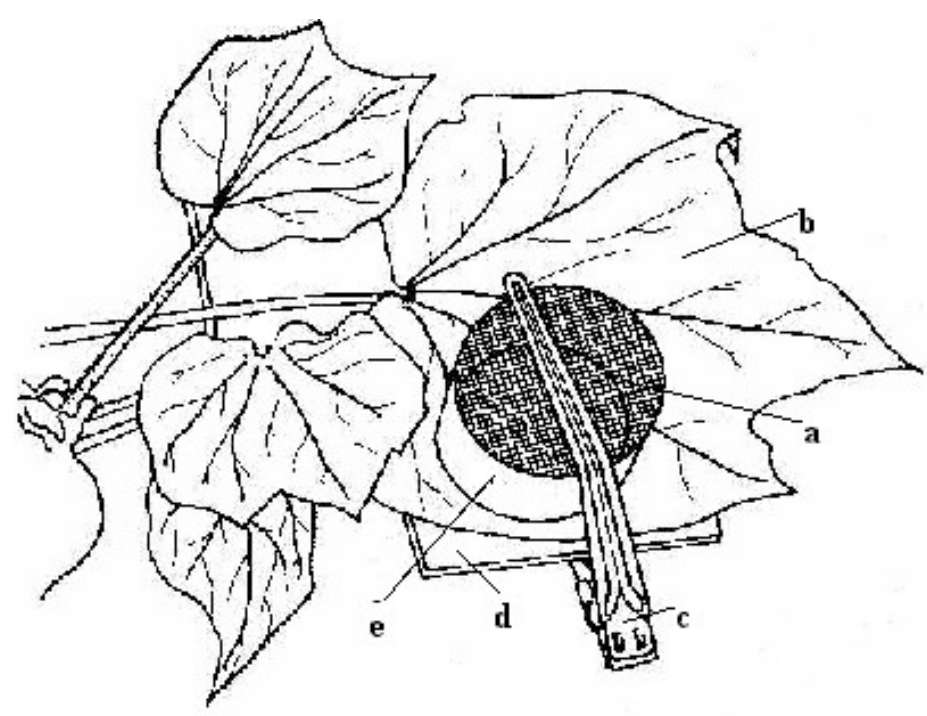

FIGURA 1 - Gaiola plástica utilizada para o confinamento das fases imaturas de Chrysoperla externa: (a) tecido organza, (b) folha do algodoeiro, (c) presilha de metal, (d) base de plástico e (e) gaiola plástica. 
TABELA 1 - Período embrionário (dias) e viabilidade $(\%)( \pm \mathrm{EP})^{1}$ de ovos de Chrysoperla externa em casa-devegetação em diferentes recipientes de criação. UFLA, Lavras - MG, 2000.

\begin{tabular}{lcl}
\multicolumn{1}{c}{ Recipientes } & Período embrionário & Viabilidade \\
\hline Tubo de vidro & $6,3 \pm 0,2 \mathrm{~A}$ & $75,6 \pm 5,8 \mathrm{~B}$ \\
\hline Gaiola plástica & $6,5 \pm 0,9 \mathrm{~A}$ & $71,1 \pm 2,0 \mathrm{~B}$ \\
\hline Gaiola de pvc sem umidificador & $7,6 \pm 0,7 \mathrm{~A}$ & $88,0 \pm 5,0 \mathrm{~A}$ \\
\hline Gaiola de pvc com umidificador & $7,5 \pm 0,5 \mathrm{~A}$ & $76,0 \pm 6,2 \mathrm{~B}$ \\
\hline
\end{tabular}

Médias seguidas pela mesma letra nas colunas não diferem entre si pelo teste de Scott e Knott $(\mathbf{p} \leq \mathbf{0 , 0 5})$

$1=$ erro padrão

TABELA 2 - Duração (dias), número de ovos predados e viabilidade $(\%)( \pm \mathrm{EP})^{1}$ de larvas de Chrysoperla externa alimentadas com ovos de Anagasta kuehniella, em casa-de-vegetação. UFLA, Lavras - MG, 2000.

\begin{tabular}{lcccccc}
\hline \multirow{2}{*}{ Ínstares } & \multicolumn{2}{c}{ Duração } & \multicolumn{2}{c}{ Capacidade predatória } & \multicolumn{2}{c}{ Viabilidade } \\
\cline { 2 - 7 } & $\begin{array}{c}\text { Tubo } \\
\text { de vidro }\end{array}$ & $\begin{array}{c}\text { Gaiola } \\
\text { plástica }\end{array}$ & Tubo de vidro & Gaiola plástica & $\begin{array}{c}\text { Tubo } \\
\text { de vidro }\end{array}$ & $\begin{array}{c}\text { Gaiola } \\
\text { tica }\end{array}$ \\
\hline Primeiro & $2,4 \pm 0,2 \mathrm{aA}$ & $2,4 \pm 0,1 \mathrm{aA}$ & $266,6 \pm 28,0 \mathrm{aB}$ & $222,4 \pm 22,2 \mathrm{aC}$ & $77,4 \pm 3,9 \mathrm{aA}$ & $73,7 \pm 4,1 \mathrm{aA}$ \\
\hline Segundo & $1,5 \pm 0,1 \mathrm{aB}$ & $1,8 \pm 0,1 \mathrm{aB}$ & $391,8 \pm 44,4 \mathrm{aB}$ & $386,8 \pm 52,5 \mathrm{aB}$ & $76,8 \pm 3,9 \mathrm{aA}$ & $68,0 \pm 4,1 \mathrm{aA}$ \\
\hline Terceiro & $2,3 \pm 0,1 \mathrm{aA}$ & $1,6 \pm 0,1 \mathrm{bB}$ & $2630,0 \pm 224,8 \mathrm{aA}$ & $1919,9 \pm 151,6 \mathrm{bA}$ & $76,9 \pm 4,0 \mathrm{aA}$ & $68,6 \pm 4,1 \mathrm{aA}$ \\
\hline
\end{tabular}

Médias seguidas pela mesma letra minúscula nas linhas e maiúscula nas colunas não diferem entre si pelo teste de Scott e Knott $(P \leq \mathbf{0 , 0 5})$.

1 = erro padrão.

A temperatura na casa-de-vegetação também afetou o consumo das larvas, verificando-se uma correlação negativa entre a capacidade predatória e esse fator, com um maior número de ovos predados em temperaturas mais baixas (Tabela 3). Esses resultados foram coincidentes com aqueles obtidos por Maia et al. (2000), os quais verificaram que a elevação da temperatura até $30^{\circ} \mathrm{C}$ promoveu um aumento progressivo na velocidade de desenvolvimento de $C$. externa e, por conseguinte, menor duração de cada fase e redução no número de presas consumidas. O número de ovos de A. kuehniella predados por larvas de C. externa foi superior ao verificado por Caetano (1995) e Caetano et al. (1996), que observaram um consumo de 95,8, 192,4 e 1.264,9 ovos dessa mesma espécie de lepidóptero, para os três ínstares, respectivamente, com um consumo total de 1.553 ovos.
Os resultados obtidos para a viabilidade da fase de larva demonstraram que não houve diferenças significativas entre os tipos de recipientes em cada ínstar, bem como entre os ínstares em cada recipiente (Tabela 2). Observou-se que o tipo de gaiola influenciou a viabilidade da fase de larva, provavelmente devido às diferenças entre os seus volumes ou às condições proporcionadas pela folha do algodoeiro no interior das gaiolas plásticas. A temperatura, umidade relativa e estádio de desenvolvimento não afetaram a viabilidade da fase larval, não sendo detectada correlação significativa entre eles. Os resultados obtidos para essa variável (Tabela 2) foram inferiores àqueles encontrados por Caetano (1995) e Caetano et al. (1996), os quais observaram que a viabilidade larval de C. externa, em função dos ínstares e em condições ambientais controladas, foi de 97; 100 e $100 \%$, respectivamente. 
TABELA 3 - Correlações de Pearson entre o recipiente de criação, temperatura, umidade relativa do ar e os três ínstares de Chrysoperla externa, em casa-de-vegetação. UFLA, Lavras - MG, 2000.

\begin{tabular}{llccc}
\hline \multicolumn{1}{c}{ Variáveis } & Parâmetros & Correlação & T & Significância \\
\hline Recipiente & Duração & 0,0745 & 1,1278 & $0,1297 \mathrm{~ns}$ \\
\hline Recipiente & Consumo & 0,0985 & 1,4947 & $0,0675 \mathrm{~ns}$ \\
\hline Recipiente & Viabilidade & 0,1373 & 2,0968 & $0,0180 *$ \\
\hline Temperatura & Duração & 0,0582 & 0,8806 & $0,1893 \mathrm{~ns}$ \\
\hline Temperatura & Consumo & $-0,1887$ & $-2,9019$ & $0,0019 *$ \\
\hline Temperatura & Viabilidade & 0,0555 & 0,8412 & $0,2001 \mathrm{~ns}$ \\
\hline Umidade & Duração & $-0,0538$ & $-0,8129$ & $0,2081 \mathrm{~ns}$ \\
\hline Umidade & Consumo & 0,0134 & 0,2030 & $0,4196 \mathrm{~ns}$ \\
\hline Umidade & Viabilidade & $-0,0257$ & $-0,3890$ & $0,3487 \mathrm{~ns}$ \\
\hline Ínstares & Duração & $-0,1906$ & $-2,9322$ & $0,0017 *$ \\
\hline Ínstares & Consumo & 0,7066 & 15,0783 & $0,0001 *$ \\
\hline Ínstares & Viabilidade & $-0,0440$ & $-0,6665$ & $0,2525 \mathrm{~ns}$ \\
\hline
\end{tabular}

$*$ = significativo $(\mathbf{P} \leq \mathbf{0 , 0 5})$.

ns = não-significativo.

Recipiente $=$ gaiola plástica e tubo de vidro.

$\mathbf{T}=$ valor do teste.

A duração da fase de larva não foi influenciada pelo tipo de recipiente, variando de 5,5 $\pm 0,4$ a 6,1 $\pm 0,4$ dias. Da mesma forma, a viabilidade dessa fase foi semelhante para as larvas criadas em gaiolas plásticas e para aquelas mantidas em tubos de vidro, com uma variação de 67,9 \pm 3,9 e $74,4 \pm 3,9 \%$, respectivamente. Independente do tipo de recipiente de criação utilizado, foi possível um completo desenvolvimento larval, com uma viabilidade relativamente alta para indivíduos criados em condições semiartificiais. Em laboratório, Maia (1998) e Fonseca et al. (2000) verificaram, para larvas de C. externa alimentadas com o pulgão Schizaphis graminum (Rondani, 1852) (Hemiptera: Aphididae), uma viabilidade superior a $70 \%$. Pode-se verificar uma proximidade dos resultados obtidos em casa-de-vegetação e aqueles oriundos de experimentos conduzidos em laboratório, com a mesma espécie de crisopídeo. Deve-se ressaltar que, além das diferenças quanto às condições ambientais, o alimento fornecido às larvas pode ter sido um fator importante para a determinação da viabilidade dessa fase do desenvolvimento.
A duração da fase de pupa foi de 13,5 $\pm 0,3$ e 13,1 \pm 0,4 dias, em gaiola plástica e tubo de vidro, respectivamente, não sendo detectada diferença significativa entre as médias. A viabilidade de pupas provenientes de larvas alimentadas com ovos de A. kuehniella foi de $65,8 \%$ em gaiola plástica e $52,9 \%$ em tubos de vidro. Esses resultados diferiram daqueles encontrados por Ribeiro (1988) que, estudando larvas dessa mesma espécie de crisopídeo criadas em tubos de vidro com as mesmas dimensões, mantidas a $25 \pm 2{ }^{\circ} \mathrm{C}, 70 \pm 10 \%$ de umidade relativa e alimentadas com ovos de Alabama argillacea (Hübner, 1818) (Lepidoptera: Noctuidae), obteve 100\% de sobrevivência para essa fase. Carvalho et al. (1998), alimentando larvas de $C$. externa com ovos desse mesmo noctuídeo, também verificaram uma viabilidade de 92\%. Essas constatações, embora evidenciem um efeito negativo das oscilações da temperatura em condições de casa-de- vegetação, refletem uma maior proximidade das condições a que esses insetos estão naturalmente expostos. 
Não houve diferenças significativas no período de pré-oviposição de adultos alimentados com qualquer das dietas testadas, independentemente da sua consistência, constatando-se uma variação de 6,0 \pm 0,4 a 8,7 \pm 1,7 dias (Tabela 4). A duração do período de préoviposição de $C$. externa em casa-de-vegetação foi maior que a obtida por Ribeiro et al. (1993), que alimentando adultos da mesma espécie com lêvedo de cerveja e mel, a $25 \pm 2{ }^{\circ} \mathrm{C}$, observaram uma duração de 3,0 dias, resultado próximo ao constatado por Ribeiro (1998), que obteve 2,6 dias para insetos criados nas mesmas condições ambientais.

O período de oviposição foi influenciado pelo tipo e consistência da dieta, verificando-se que os insetos alimentados com a dieta semilíquida tiveram um período de oviposição maior quando supridos com lêvedo de cerveja e mel, não apresentando diferenças significativas na duração desse período quando alimentados com extrato de soja e pólen. Fornecendo-se a dieta na forma pastosa, o período de oviposição foi menor para adultos que receberam pólen, não diferindo entre si quando alimentados com as dietas à base de lêvedo de cerveja e extrato de soja (Tabela 4).

Para adultos que receberam extrato de soja ou pólen, não houve diferenças significativas na duração do período de oviposição em função da consistência; porém, aqueles que foram alimentados com lêvedo de cerveja apresentaram uma duração maior quando fornecida na forma semilíquida (38,0 $\pm 7,0$ dias). $O$ fato de o pólen utilizado ser oriundo de diversas espécies vegetais pode ter influenciado nos resultados obtidos, possivelmente em razão de algum efeito na fisiologia dos adultos. Pannizi \& Parra (1991) citaram que em alguns polens são encontrados mais de 14 carboidratos que participam de processos geradores de energia e síntese protéica nos insetos, seja fornecido com outros ingredientes da dieta ou isoladamente. De maneira geral, verificou-se para todas as dietas testadas que, quando oferecidas na consistência semilíquida, permitiram um prolongamento do período de oviposição, em relação à pastosa, pois, naquela consistência, o alimento pode ser facilmente ingerido por mais tempo.

Os resultados obtidos para a duração do período de oviposição foram inferiores àqueles verificados por Aun (1986), que observou uma duração de 74 dias. Também discreparam daqueles verificados por Ribeiro et al. (1993) que, trabalhando com a mesma espécie de crisopídeo em condições de laboratório, observaram uma duração de 100,5 dias para fêmeas alimentadas com pólen e mel. Uma duração de 81 dias foi constatada por Ribeiro (1998), quando as fêmeas foram alimen- tadas com lêvedo de cerveja e mel e de 53 dias quando a essa dieta foi adicionado diamônio fosfato a $8 \%$, acarretando uma redução de 28 dias na duração desse período. Esses resultados demonstram as diferenças verificadas em experimentos conduzidos em laboratório que, embora de suma importância para o conhecimento dos aspectos biológicos de $C$. externa, diferem daqueles conduzidos em condições de semicampo e campo.

O período efetivo de oviposição não foi afetado pelo tipo e consistência da dieta ingerida, porém, de uma maneira geral e como constatado para o período de oviposição, as dietas semi-líquidas proporcionaram um maior número de dias de postura, em relação à forma pastosa. Os resultados obtidos foram menores que aqueles verificados para essa mesma espécie de crisopídeo por Ribeiro et al. (1993), que constataram que a dieta composta por pólen e mel prolongou por 95 dias a duração desse período.

Observou-se que as fêmeas de $C$. externa tiveram sua capacidade de oviposição diária influenciada pelo tipo e pela consistência das dietas. Aquelas à base de lêvedo de cerveja e extrato de soja na forma pastosa proporcionaram uma maior produção de ovos em relação àquela a base de pólen. Para a consistência semilíquida, a dieta de lêvedo de cerveja permitiu a maior produção de ovos, seguida daquela de pólen e por aquela à base de extrato de soja. Com relação à consistência, observou-se que adultos mantidos com as dietas à base de lêvedo de cerveja e extrato de soja apresentaram uma maior oviposição quando oferecidas na forma pastosa; contudo, para a dieta de pólen não houve efeito desse fator sobre a produção diária de ovos.

Os resultados obtidos foram inferiores aos observados por Ribeiro (1998), para adultos de C. externa alimentados com lêvedo de cerveja e mel, que verificou uma produção diária de 30,4 ovos/fêmea, a $25 \pm 2{ }^{\circ} \mathrm{C}$ e umidade relativa de $75 \pm 10 \%$.

Para a capacidade total de oviposição, a consistência das dietas não afetou o número de ovos produzidos durante todo o período de vida da fêmea (Tabela 4). Quando fornecida na forma semilíquida, o lêvedo de cerveja proporcionou uma produção de ovos cerca de cinco vezes superior ao total produzido por fêmeas que receberam as demais dietas. Na forma pastosa, as dietas à base de lêvedo de cerveja e extrato de soja permitiram uma maior produção de ovos em relação àquela formulada à base de pólen. Contudo, pôde-se verificar que o número de ovos produzidos pelas fêmeas alimentadas com lêvedo de cerveja foi mais de duas vezes aquele verificado por aquelas supridas com extrato de soja, nessa mesma consistência.

Ciênc. agrotec., Lavras. V.27, n.1, p.7-16, jan./fev., 2003 


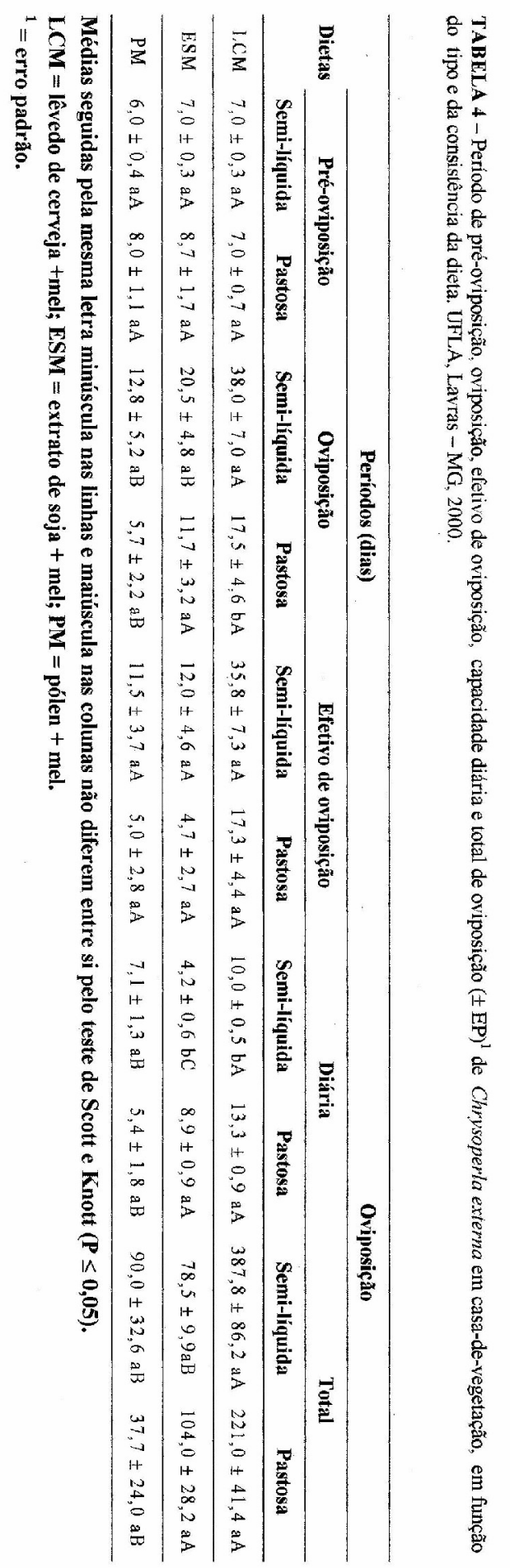

Ciênc. agrotec., Lavras. V.27, n.1, p.7-16, jan./fev., 2003 
Esses resultados foram inferiores aos observados por Ribeiro et al. (1993) quando alimentaram um grupo de fêmeas de $C$. externa com uma dieta à base de lêvedo de cerveja e mel, e outro com proteína texturizada de soja e mel, oferecidas na consistência pastosa, constatando-se uma produção de 2.273 e 1.985 ovos, respectivamente. Isso foi devido, possivelmente, ao fato de os experimentos terem sido conduzidos em laboratório, onde as condições ambientais foram controladas.

A longevidade observada para fêmeas que receberam as dietas na consistência semi-líquida foi maior quando mantidas com lêvedo de cerveja, não havendo diferenças significativas entre as demais. Aquelas alimentadas com as dietas na consistência pastosa apresentaram uma longevidade semelhante, com uma variação de $19,2 \pm 4,2$ a $23,0 \pm 4,4$ dias.

A maior longevidade foi obtida para fêmeas alimentadas com lêvedo de cerveja na forma semilíquida, sendo de 45,5 \pm 3,8 dias, ao passo que as demais dietas não proporcionaram diferenças significativas em função da consistência, proporcionando uma duração de aproximadamente 20 dias. Em pesquisas conduzidas por Perez et al. (1984) com a mesma espécie de crisopídeo alimentada com uma dieta composta de pólen, mel e água, as fêmeas apresentaram uma longevidade média de 48 dias, em laboratório. Ribeiro et al. (1993) verificaram que fêmeas supridas com pólen puro, proteína texturizada de soja + mel, lêvedo de cerveja + mel ou solução de mel a $40 \%$ não tiveram a sua longevidade afetada pelo tipo de alimento ingerido.

\section{CONCLUSÕES}

a) A viabilidade dos ovos de C. externa foi influenciada negativamente em recipientes com maior umidade relativa do ar.

b) A capacidade predatória de larvas de C. exter$n a$ foi afetada negativamente em temperaturas mais elevadas.

c) A duração e a viabilidade de ovos, larvas e pupas de C. externa não foram afetadas pelo tipo de recipiente de criação.

d) O consumo de ovos de A. kuehniella foi maior para larvas de terceiro ínstar criadas em tubo de vidro.

e) A duração do período de pré-oviposição de $C$. externa não foi afetada pelo tipo ou pela consistência do alimento fornecido.

f) Lêvedo de cerveja, mel e água na consistência semilíquida foi a melhor dieta para adultos de C. externa, permitindo a maior fecundidade.

\section{AGRADECIMENTO}

Ao Banco do Nordeste do Brasil S.A. - BNB, pela colaboração financeira para a execução deste trabalho, parte do projeto "Controle biológico do curuquerêdo-algodoeiro com o emprego de Chrysoperla externa".

\section{REFERÊNCIAS BIBLIOGRÁFICAS}

AUN, V. Aspectos da biologia de Chrysoperla externa (Hagen, 1861) (Neuroptera: Chrysopidae). 1986. 65 p. Dissertação (Mestrado em Ciências Biológicas) Escola Superior de Agricultura "Luiz de Queirós", Piracicaba.

CAETANO, A. C. Capacidade de consumo de Chrysoperla externa (Hagen, 1861) (Neuroptera: Chrysopidae) em diferentes presas, sob condições de laboratório. 1995. 41 p. Dissertação (Mestrado em Agronomia) - Faculdade de Ciências Agrícola e Veterinária, Jaboticabal.

CAETANO, A. C.; MURATA, A. T.; DE BORTOLI, S. A.; NARCISO, R. S. Estudo da capacidade de consumo de Chrysoperla externa (Hagen, 1861) (Neuroptera: Chrysopidae) em diferentes presas, sob condições de laboratório. In: SIMPÓSIO DE CONTROLE BIOLÓGICO, 5., 1996, Foz do Iguaçu. Resumos... Foz do Iguaçu: Sociedade Entomológica do Brasil, 1996. p. 22.

CARVALHO, C. F.; SOUZA, B. Métodos de criação e produção de crisopídeos. In: BUENO, V. H. P. (Ed.). Controle biológico de pragas: produção massal e controle de qualidade. Lavras: UFLA, 2000. p. 91-109.

CARVALHO, C. F.; SOUZA, B.; SANTOS, T. M. Predation capacity and reproduction potential of Chrysoperla externa (Hagen) (Neuroptera: Chrysopidae) fed on Alabama argillacea (Hübner) eggs. Acta Zoologica Fennica, Helsinki, v. 209, p. 8386, 1998.

CLIMANÁLISE. Boletim de Monitoramento e Análise Climática, Cachoeira Paulista, v. 13, n. 6, p. 45, 1998.

FIGUEIRA, L. K.; CARVALHO, C. F.; SOUZA, B. Influência da temperatura sobre alguns aspectos biológicos de Chrysoperla externa (Hagen, 1861) (Neuroptera: Chrysopidae) alimentada com ovos de Alabama argillacea (Hübner, 1818) (Lepidoptera: Noctuidae). Ciência e Agrotecnologia, Lavras, 2001. (No prelo). 
FONSECA, A. R.; CARVALHO, C. F.; SOUZA, B. Resposta funcional de Chrysoperla externa (Hagen, 1861) (Neuroptera: Chrysopidae) alimentada com Schizaphis graminum (Rondani, 1852) (Hemiptera: Aphididae). Anais da Sociedade Entomológica do Brasil, Jaboticabal, v. 29, n. 2, p. 309-317, 2000.

GITIRANA NETO, J.; CARVALHO, C. F.; SOUZA, B.; SANTA-CECÍLIA, L. V. C. Flutuação populacional de espécies de Ceraeochrysa Adams, 1982 (Neuroptera: Chrysopidae) em citros, na região de Lavras - MG. Ciência e Agrotecnologia, Lavras, v. 25, n. 3, p. 550$559,2001$.

MAIA, W. J. M. S. Aspectos biológicos e exigências térmicas da fase jovem de Chrysoperla externa (Hagen, 1861) (Neuroptera: Chrysopidae) alimentada com $S$ chizaphis graminum (Rondani, 1852) (Homoptera: Aphididae). 1998. 66 p. Dissertação (Mestrado em Agronomia) - Universidade Federal de Lavras, Lavras.

MAIA, W. J. M. S.; CARVALHO, C. F.; SOUZA, B. Exigências térmicas de Chrysoperla externa (Hagen, 1861) (Neuroptera: Chrysopidae) alimentada com Schizaphis graminum (Rondani, 1852) (Homoptera: Aphididae) em condições de laboratório. Ciência e Agrotecnologia, Lavras, v. 24, n. 1, p. 74-80, 2000.

PANIZZI, A. R.; PARRA, J. R. P. Ecologia nutricional de insetos e suas implicações no manejo de pragas. São Paulo: Manole, 1991. 359 p.

PEREZ, C. A.; KOMATSU, S.; NAKANO, O.; PARRA J. R. P. Dieta para adultos de Chrysoperla externa (Hagen, 1861) (Neuroptera: Chrysopidae) e alguns aspectos referentes a sua biologia. In: CONGRESSO BRASILEIRO DE ENTOMOLOGIA,
9., 1984, Londrina. Resumos... Londrina: Sociedade Entomológica do Brasil, 1984. p. 72.

RIBEIRO, L. J. Características do desenvolvimento e potencial reprodutivo de Chrysoperla externa (Hagen, 1861) (Neuroptera: Chrysopidae) sob diferentes dietas alimentares. 112 p. 1998. Dissertação (Mestrado em Agronomia) - Universidade do Estado de São Paulo, Jaboticabal.

RIBEIRO, M. J. Biologia de Chrysoperla externa (Hagen, 1861) (Neuroptera: Chrysopidae), alimentada com diferentes dietas. 1988. 131 p. Dissertação (Mestrado em Agronomia) - Escola Superior de Agricultura de Lavras, Lavras.

RIBEIRO, M. J.; CARVALHO, C. F.; MATIOLI, J. C. Biologia de adultos de Chrysoperla externa (Hagen, 1861) (Neuroptera: Chrysopidae) em diferentes dietas artificiais. Ciência e Prática, Lavras, v. 17, n. 2, p. 120-130, 1993.

SCOTT, A. J.; KNOTT, M. A. Cluster analysis method for grouping means in the analysis of variances. Biometrics, Washington, v. 30, n. 3, p. 507-512, 1974.

SOUZA, B; CARVALHO, C. F. Population dynamics and seasonal occurrence of adults of Chrysoperla externa (Hagen, 1861) (Neuroptera: Chrysopidae) in a citrus orchard in southern Brazil. Acta Zoologica Academiae Scientiarum Hungaricae, Budapest, v. 47, n. 2/3, p. 295-304, 2001. 